\title{
The use of insecticide treated nets by age: implications for universal
} coverage in Africa

\author{
Abdisalan M Noor*1,2, Viola C Kirui ${ }^{1}$, Simon J Brooker ${ }^{1,3}$ and \\ Robert W Snow ${ }^{1,2}$
}

\begin{abstract}
Address: ${ }^{1}$ Malaria Public Health and Epidemiology Group, Centre for Geographic Medicine, KEMRI - University of Oxford - Wellcome Trust Collaborative Programme, Kenyatta National Hospital Grounds (behind NASCOP), P.O. Box 43640-00100, Nairobi, Kenya, ${ }^{2}$ Centre for Tropical Medicine, Nuffield Department of Clinical Medicine, University of Oxford, CCVTM, Oxford OX3 7LJ, UK and ${ }^{3}$ Department of Infectious and Tropical Diseases, London School of Hygiene and Tropical Medicine, London, UK

Email: Abdisalan M Noor* - anoor@nairobi.kemri-wellcome.org; Viola C Kirui - vkirui@nairobi.kemri-wellcome.org; Simon J Brooker - sbrooker@nairobi.kemri-wellcome.org; Robert W Snow - rsnow@nairobi.kemri-wellcome.org

* Corresponding author
\end{abstract}

Published: I October 2009

BMC Public Health 2009, 9:369 doi:10.1 186/147|-2458-9-369

This article is available from: http://www.biomedcentral.com/I47I-2458/9/369

(C) 2009 Noor et al; licensee BioMed Central Ltd.

This is an Open Access article distributed under the terms of the Creative Commons Attribution License (http://creativecommons.org/licenses/by/2.0), which permits unrestricted use, distribution, and reproduction in any medium, provided the original work is properly cited.
Received: 22 June 2009

Accepted: I October 2009

\begin{abstract}
Background: The scaling of malaria control to achieve universal coverage requires a better understanding of the population sub-groups that are least protected and provide barriers to interrupted transmission. Here we examine the age pattern of use of insecticide treated nets (ITNs) in Africa in relation to biological vulnerabilities and the implications for future prospects for universal coverage.
\end{abstract}

Methods: Recent national household survey data for 18 malaria endemic countries in Africa were assembled to indentify information on use of ITNs by age and sex. Age-structured medium variant projected population estimates for the mid-point year of the earliest and most recent national surveys were derived to compute the population by age protected by ITNs.

Results: All surveys were undertaken between 2005 and 2009, either as demographic health surveys $(n=12)$ or malaria indicator surveys $(n=6)$. Countries were categorized into three ITN use groups: $<10 \%$; 10 to $<20 \%$; and $\geq 20 \%$ and projected population estimates for the mid-point year of 2007 were computed. In general, the pattern of overall ITNs use with age was similar by country and across the three country groups with ITNs use initially high among children $<5$ years of age, sharply declining among the population aged 5-19 years, before rising again across the ages 20-44 years and finally decreasing gradually in older ages. For all groups of countries, the highest proportion of the population not protected by ITNs (38\% - 42\%) was among those aged 5-19 years.

Conclusion: In malaria-endemic Africa, school-aged children are the least protected with ITNs but represent the greatest reservoir of infections. With increasing school enrollment rates, schooldelivery of ITNs should be considered as an approach to reach universal ITNs coverage and improve the likelihood of impacting upon parasite transmission. 


\section{Background}

The slow progress toward the target set by African heads of state in Abuja in 2001 of $60 \%$ coverage of insecticidetreated nets (ITNs) among vulnerable children and pregnant women [1] has, in recent years, shown promising signs of changing with rapid scaling-up of ITNs coverage in many African countries [2]. However the Abuja target, and the Millennium Develop Goal 6 (80\% coverage of children and pregnant women) [3], do not account for scaling ITN to achieve high coverage of all population segments necessary to reduce malaria transmission and protect communities. The scaling of ITNs demands a shift from prioritizing vulnerable populations to protecting everyone, including the most vulnerable, by achieving high coverage and community-wide use of ITNs. ITNs at high coverage levels impact vector population survival and abundance, where those not sleeping under an ITN will benefit and a mass-effect is achieved. The latter has been observed during trials of ITNs during the 1990's [48]. Theoretical models strongly support the likely benefit of levels of coverage beyond those most vulnerable to the clinical burden posed by Plasmodium falciparum $[9,10]$. Underpinning these models is the fact that it is estimated that $80 \%$ of human-to-mosquito transmission originates from human hosts older than 5 years of age, with $P$. falciparum prevalence, under stable malaria transmission, rising during early childhood, peaking in older children and falling through adolescence and adulthood [11].

There are now extensive temporal data on ITNs coverage across Africa since 2000 generated as part of national household cluster sample surveys $[2,12,13]$. These data have been used to examine progress toward coverage of ITNs among children under five years of age and pregnant women $[2,12,14]$ or determinants of use $[15,16]$. Inevitably survey tools and indicators were developed around international targets established 10 years ago and thus most data focus on coverage of ITNs among the vulnerable groups or provide some indication of ownership among households. Notable is the paucity of data presented on coverage and use by age and sex across the entire surveyed community.

Following recent calls for universal coverage of ITNs and other vector control strategies [17], and given the biological basis for the target, we have analyzed datasets from those recent national surveys that describe coverage by age and sex among all members of a household.

\section{Methods}

Household survey data on coverage of ITNs (defined as pretreated nets obtained within the last 12 months or nets that have been soaked with insecticide within the past 12 months or a long lasting insecticidal net (LLIN)) were sought from three principal sources: a) demographic and health surveys (DHS) [18]; b) malaria indicator surveys (MIS) undertaken by national malaria programmes using a package of standardized tools developed by the Roll Back Malaria [19]; and c) multiple indicators cluster surveys (MICS) supported by the United Nations Children's Fund [20]. These surveys are designed to be nationally representative with a sample size often of more than 3,000 households derived from a two-stage cluster sample design and are typically conducted every 3-5 years in collaboration with national ministries of health and statistics bureaus. Not all surveys contained information on ITNs use among all household members. No national surveys undertaken before 2005 contained information on ITNs use by all ages. 32 malaria endemic countries had undertaken national surveys since 2005 where data were available for download (14 DHS; 6 MIS; and 12 MICS). None of the MICS reported ITNs use by all ages. MIS have been completed for Mozambique (2007), Ethiopia (2007) and Eritrea (2008) but these data were not available online at the time of analysis. For Ethiopia, however, the DHS 2005 which contained ITNs use by all ages was used instead. In Congo and Liberia, DHS were completed between 2005 and 2007 but neither had information on ITNs use among all household members. Information was therefore available for a detailed analysis of the age and sex patterns of ITNs use among all household members from 18 malaria endemic countries in Africa undertaken between 2005 and 2009 as part of DHS ( $\mathrm{n}=12)$ or MIS (6) (Table 1$)$. Plots of ITNs use overall and by gender were constructed by age for each country separately (see Additional file 1). Countries were ranked based on the proportion of individuals of all ages sleeping under an ITNs the night before survey and were then aggregated into three groups - Country Group 1 ( $\geq$ 20\%: Kenya, Tanzania, Mali, Zambia), Country Group 2 (10\% - < 20\%: Benin, Senegal, Angola, Djibouti, Sudan) and Country Group 3 (<10\%: Rwanda, Uganda, Namibia, Niger, DRC, Zimbabwe, Ethiopia, Guinea, Swaziland). To estimate the numbers of individuals unprotected in each country the medium variant agestructured projected population estimates for 2007 from the United Nation's World Population Prospects database was used [21]. The period 2007 was selected as the midpoint of the assembled national surveys all of which were undertaken between 2005 and 2009.

\section{Results}

In general, the pattern of overall ITNs use with age was similar by country (see Additional file 1) and across the three country groups with ITNs use initially high among children $<5$ years of age, sharply declining among the population aged 5-19 years, before rising again across the ages 20-44 years and finally decreasing gradually in older ages (Table 1, Figures 1a-1c). This trend, however, was more pronounced with increasing overall ITNs coverage (Figure 1a). When the pattern of ITNs use was viewed by 
Table I: Summary of national households surveys with data on ITN use among all age-groups in African countries where national surveys reported information on all ages: countries are ranked from highest to lowest based on the proportion of individuals of all ages who slept under an ITN the night prior to survey.

\begin{tabular}{|c|c|c|c|c|c|c|c|c|c|c|c|}
\hline & Country & Survey & Year & Month & $\begin{array}{l}\text { Number of } \\
\text { clusters } \\
\text { sampled for } \\
\text { survey }\end{array}$ & $\begin{array}{l}\text { Number of } \\
\text { households } \\
\text { samples for } \\
\text { survey }\end{array}$ & $\begin{array}{l}\text { Number of } \\
\text { persons } \\
\text { seen during } \\
\text { survey }\end{array}$ & $\begin{array}{l}\text { Number of } \\
\text { ITN owned } \\
\text { by the } \\
\text { sampled } \\
\text { households }\end{array}$ & $\begin{array}{c}\% \text { of } \\
\text { household } \\
\text { with at least } \\
\text { two ITN }\end{array}$ & $\begin{array}{c}\text { \% of children } \\
<5 \text { years old } \\
\text { sleeping } \\
\text { under ITN } \\
\text { the night } \\
\text { before } \\
\text { survey }\end{array}$ & $\begin{array}{l}\text { \% of persons } \\
\text { of all ages } \\
\text { sleeping } \\
\text { under ITN } \\
\text { the night } \\
\text { before } \\
\text { survey }\end{array}$ \\
\hline \multirow[t]{4}{*}{ Group I } & Kenya & MIS & 2007 & June-July & 200 & 6,854 & 31,297 & 5,483 & 22.5 & 39.2 & 38.9 \\
\hline & Tanzania & AIS/MIS & $2007-8$ & $\begin{array}{l}\text { October- } \\
\text { February }\end{array}$ & 475 & 8,497 & $4|, 87|$ & 5,948 & 18.8 & 32.3 & 29.4 \\
\hline & Zambia & DHS & 2007 & April-October & 319 & 7,164 & 35,562 & 8,486 & 24.9 & 29.1 & 23.9 \\
\hline & Mali & DHS & 2006 & $\begin{array}{c}\text { April- } \\
\text { September }\end{array}$ & 408 & 12,998 & 73,685 & $|5,62|$ & 25.2 & 27.3 & 21.2 \\
\hline \multirow[t]{5}{*}{ Group 2} & Benin & DHS & 2006 & $\begin{array}{l}\text { July- } \\
\text { November }\end{array}$ & 750 & $|7,5| 1$ & 90,650 & 12,790 & 10.3 & 19.7 & 14.1 \\
\hline & Senegal & MIS & 2006 & $\begin{array}{l}\text { November- } \\
\text { December }\end{array}$ & 150 & 3,063 & 30,199 & 3,998 & 21.7 & 16.2 & 13.2 \\
\hline & Angola & MIS & $2006-7$ & $\begin{array}{l}\text { November- } \\
\text { April }\end{array}$ & 120 & 2,599 & 14,399 & 1,040 & 10.9 & 17.7 & 13.0 \\
\hline & Djibouti & MIS & $2008-9$ & $\begin{array}{l}\text { December- } \\
\text { February }\end{array}$ & 156 & 3,603 & 22,373 & 1,802 & 17.6 & 19.9 & 13.0 \\
\hline & Sudan & MIS & 2005 & October & 143 & 2,460 & 10,639 & 1,194 & 4.8 & 15.4 & 11.3 \\
\hline \multirow[t]{9}{*}{ Group 3} & Rwanda & DHS & 2005 & February-July & 462 & 10,272 & 47,851 & 4,498 & 4.2 & 13.6 & 9.4 \\
\hline & Uganda & DHS & 2006 & May-October & 368 & 8,870 & 45,439 & 3,291 & 5.8 & 9.6 & 7.2 \\
\hline & Namibia & DHS & $2006-7$ & $\begin{array}{l}\text { October- } \\
\text { March }\end{array}$ & 500 & 9,200 & 42,633 & 2,562 & 8 & 11.1 & 6.0 \\
\hline & Niger & DHS & 2006 & January-June & 345 & 7,660 & 47,964 & 2,633 & 12.8 & 8.7 & 5.5 \\
\hline & DRC & DHS & 2007 & May-August & 300 & 8,886 & 48,291 & 2,567 & 1.9 & 7.7 & 5.3 \\
\hline & Zimbabwe & DHS & $2005-6$ & August-March & 400 & 9,285 & 40,805 & 929 & 2.5 & 3.0 & 3.3 \\
\hline & Ethiopia & DHS & 2005 & April-August & 540 & $|3,72|$ & 67,539 & 589 & 0.3 & 2.3 & 1.5 \\
\hline & Guinea & DHS & 2005 & February-June & 297 & 6,282 & 38,182 & 409 & 0.2 & 1.4 & I.I \\
\hline & Swaziland & DHS & 2006-7 & July-February & 275 & 4,843 & 22,143 & 86 & 1.2 & 0.7 & 0.4 \\
\hline
\end{tabular}

AIS = AIDS Indicator Survey; DRC = Democratic Republic of Congo; ITN = Insecticide Treated Net (a bed net treated with an insecticide the last six months prior to survey or a long lasting insecticidal net); DHS = Demographic and Health Survey; MIS = Malaria Indicator Survey. 

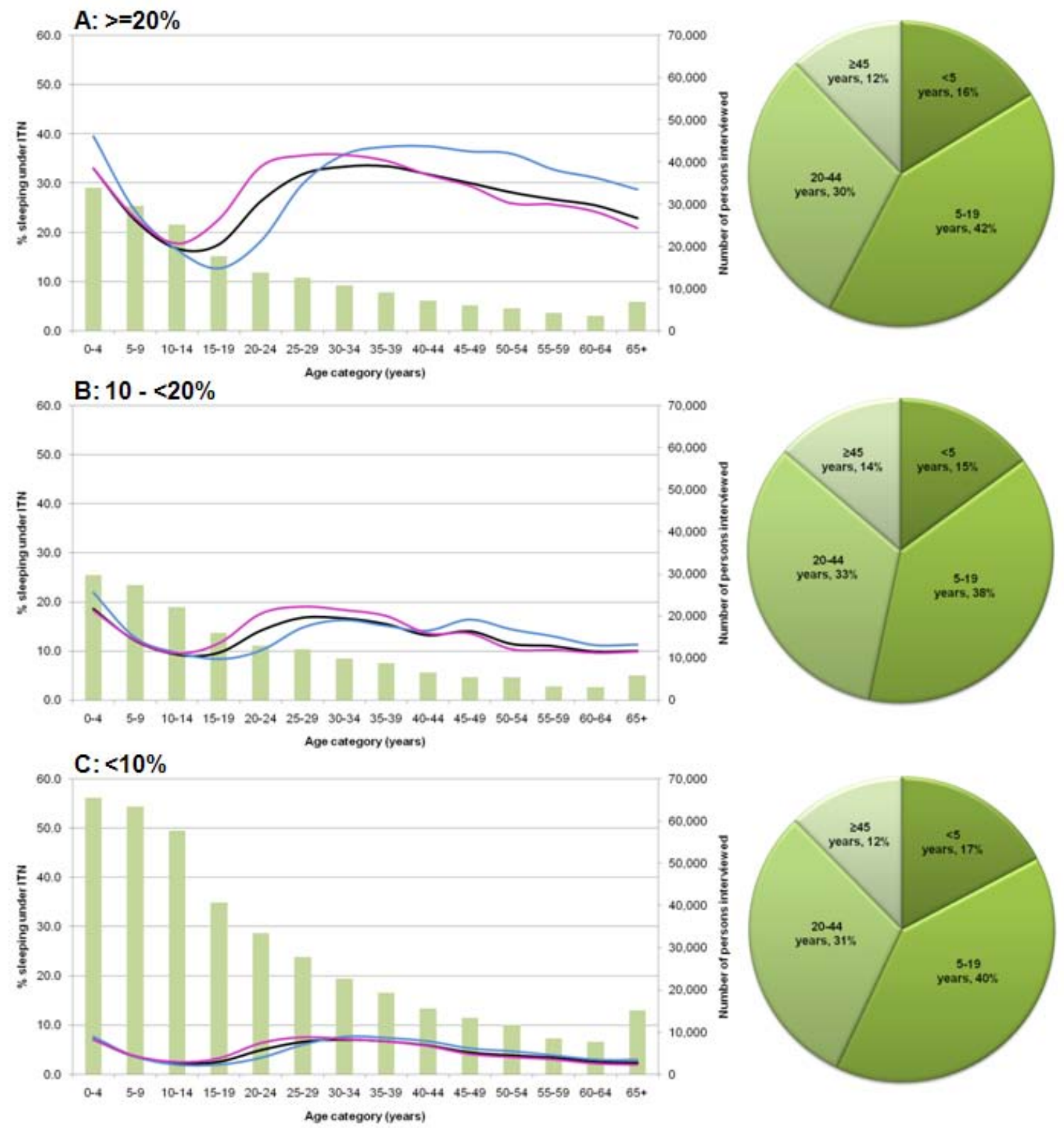

Figure I

Graphs of percentage of sample population sleeping under ITN the night before survey, overall and by gender, against the number of persons enumerated in each age category (left) and pie charts of the proportion of projected 2007 population who did not sleep under ITN by age category (right) in: A) group I: countries where $\geq$ $20 \%$ of the sample population slept under ITN (Kenya, Tanzania, Zambia, Mali); B) group 2: countries where $10-<20 \%$ of the sample population slept under ITN (Benin, Senegal, Angola, Djibouti, Sudan); C) group 3 countries where $<10 \%$ of the sample population slept under ITN (Rwanda, Uganda, Namibia, Niger, DRC, Zimbabwe, Ethiopia, Guinea, Swaziland). Pink, blue and black lines on the graphs represent the percentage female, male and total sample population sleeping under ITN the night before survey respectively. 
sex, the data showed that in the age group $<5$ years, a higher proportion of male children slept under ITNs compared to female in Country Groups 1 and 2 but no difference in Country Group 3. Between the ages of 10-34 years in Country Groups 1 and 3 and 10-44 years in Country Group 2 more females slept under ITNs compared to the males.

Population estimates and ITNs use information were arranged into four age categories: $<5$ years; $5-19$ years; 20 44 years; and $\geq 45$ years, corresponding to the traditional ITNs target groups of young children; older children and adolescents; adults most likely to have young children; and older household members at the tip of the population pyramid respectively. The proportion of individuals protected with ITNs and the total number of people not protected in each of the four age groups were recomputed and used to estimate the numbers of people un-protected in each country (Table 2). For all groups of countries, the highest proportion of the population not protected by ITNs $(38 \%-42 \%)$ was among those aged 5-19 years (Table $2 \&$ Figures 1a-c).

\section{Discussion}

Among the 18 national, household surveys analyzed across a range of overall ITNs coverage settings a common pattern of reported ITNs use emerges with highest coverage among children aged less than five years, dropping to lowest levels of coverage among children and adolescents aged 5-19 years and rising again through adulthood before a drop among the oldest household members (Figures 1a-1c). Similar differentials of ITNs use between young children and older age groups have been reported during studies in Tanzania [22-24], South Central Somalia [25], Ethiopia [26] and Nigeria [27]. The two most plausible and linked explanations for these observed patterns are that first most ITNs delivery programmes have historically focused on ensuring young children have access to nets either through routine clinic visits, attendance at regular vaccination visits, their mothers while pregnant or nets delivered as part of mass-catch-up immunization campaigns that target young children [28]. Consequently this age group would be expected, following recent efforts to scale coverage, to show the highest reported ITNs use. However, secondly this will be linked to the way people share sleeping structures in a household, where nursing and younger children will sleep with their mothers and/or both parents, who will most often be between 20-44 years of age. Conversely older children will sleep on separate beds or mats elsewhere in the household.

If scaled delivery of ITNs to young children continues to increase it may be possible to reach a point of saturation within a household as nets are shared among older siblings and other household members. However this would

Table 2: A summary of ITN use among individuals of ages < 5 years; 5-19 years; 20-44 years; and $\geq 45$ years and the estimated number of persons (millions) in each age group NOT protected with ITN in 2007: countries are ranked from highest to lowest based on the proportion of individuals of all ages who slept under an ITN the night prior to survey.

\begin{tabular}{|c|c|c|c|c|c|c|c|c|}
\hline Country & $\begin{array}{c}\text { Millions } \\
\text { children < 5 } \\
\text { years in } \\
2007 \text { (\% } \\
\text { sleeping } \\
\text { under ITN) }\end{array}$ & $\begin{array}{c}\text { Millions } \\
\text { children < } 5 \\
\text { years of age } \\
\text { NOT } \\
\text { sleeping } \\
\text { under ITN } \\
\text { in } 2007\end{array}$ & $\begin{array}{c}\text { Millions } \\
\text { children 5- } \\
19 \text { years in } \\
2007 \text { (\% } \\
\text { sleeping } \\
\text { under ITN) }\end{array}$ & $\begin{array}{l}\text { Millions } \\
\text { children 5- } \\
\text { I9 years of } \\
\text { age NOT } \\
\text { sleeping } \\
\text { under ITN } \\
\text { in } 2007\end{array}$ & $\begin{array}{c}\text { Millions of } \\
\text { persons 20- } \\
44 \text { years in } \\
2007 \text { (\% } \\
\text { sleeping } \\
\text { under ITN) }\end{array}$ & $\begin{array}{c}\text { Millions of } \\
\text { persons 20- } \\
44 \text { years of } \\
\text { age NOT } \\
\text { sleeping } \\
\text { under ITN in } \\
2007\end{array}$ & $\begin{array}{c}\text { Millions of } \\
\text { person } \geq 45 \\
\text { years of age } \\
\text { in } 2007 \text { (\% } \\
\text { not sleeping } \\
\text { under ITN) }\end{array}$ & $\begin{array}{c}\text { Millions of } \\
\text { persons } \geq 45 \\
\text { years of age } \\
\text { NOT } \\
\text { sleeping } \\
\text { under ITN in } \\
2007\end{array}$ \\
\hline Kenya & $6.32(39.2)$ & 3.80 & $14.14(30.0)$ & 9.90 & $|2.9|(43.5)$ & 7.29 & $4.46(35.5)$ & 2.87 \\
\hline Tanzania & $7.34(32.3)$ & 4.97 & $|5.6|(2 \mid .5)$ & 12.25 & I3.25 (32.5) & 8.94 & $5.22(26.2)$ & 3.82 \\
\hline Zambia & $2.23(29.1)$ & 1.58 & $4.81(16.4)$ & 4.02 & $3.83(29.6)$ & 2.70 & I.48 (26.8) & 1.08 \\
\hline Mali & $2.15(27.3)$ & 1.56 & $4.77(15.1)$ & 4.05 & $4.07(24.8)$ & 3.06 & $1.43(23.3)$ & 1.10 \\
\hline Benin & I.4I (19.7) & 1.13 & $3.12(10.6)$ & 2.79 & $2.74(17.2)$ & 2.27 & $1.13(10.4)$ & 1.01 \\
\hline Senegal & $1.99(16.2)$ & 1.67 & 4.59 (II.3) & 4.07 & $3.97(13.5)$ & 3.43 & $1.37(14.4)$ & 1.17 \\
\hline Angola & $3.14(17.7)$ & 2.58 & $6.81(7.5)$ & 6.30 & 5.55 (I5.7) & 4.68 & $2.07(13.6)$ & 1.79 \\
\hline Djibouti & 0.11 (19.9) & 0.09 & $0.30(1 \mathrm{I} .8)$ & 0.26 & $0.30(12.7)$ & 0.27 & $0.13(10.3)$ & 0.11 \\
\hline Sudan & $5.80(15.4)$ & 4.90 & $14.69(9.2)$ & 13.34 & $13.95(11.5)$ & 12.34 & $6.06(9.5)$ & 5.48 \\
\hline Rwanda & $1.61(13.6)$ & 1.39 & $3.56(5.0)$ & 3.38 & $3.21(13.8)$ & 2.77 & $1.13(6.9)$ & 1.05 \\
\hline Uganda & $6.00(9.6)$ & 5.42 & $12.52(4.4)$ & 11.97 & $9.18(10.4)$ & 8.23 & $3.04(6.4)$ & 2.85 \\
\hline Namibia & 0.27 (II.I) & 0.24 & $0.76(4.3)$ & 0.72 & $0.75(6.8)$ & 0.70 & $0.31(4)$ & 0.30 \\
\hline Niger & $2.97(8.7)$ & 2.71 & $5.52(4.2)$ & 5.28 & $4.11(6.2)$ & 3.85 & $\mathrm{I} .63(3.7)$ & 1.57 \\
\hline DRC & II.64 (7.7) & 10.75 & $24.69(3.2)$ & 23.90 & $18.92(6.9)$ & $17.6 \mid$ & $7.33(4.4)$ & 7.01 \\
\hline Zimbabwe & I.7I (3.0) & 1.66 & 5.01 (I.7) & 4.92 & $4.23(4.7)$ & 4.03 & $1.60(3.0)$ & 1.55 \\
\hline Ethiopia & I3.08 (2.3) & 12.78 & $30.37(1)$ & 30.07 & $24.82(1.9)$ & 24.35 & $10.52(0.9)$ & 10.42 \\
\hline Guinea & $1.61(1.4)$ & 1.59 & $3.58(0.7)$ & 3.56 & $3.11(1.5)$ & 3.06 & $1.36(0.9)$ & 1.35 \\
\hline Swaziland & $0.16(0.7)$ & 0.16 & $0.46(0.1)$ & 0.46 & $0.38(0.7)$ & 0.38 & $0.15(0.1)$ & 0.15 \\
\hline
\end{tabular}


depend largely on the longevity of the intact net and the insecticide. A more likely scenario is that redundancy will emerge for ITNs acquired by younger children within five years and these will be disposed of by the household or require replacement by national malaria control programmes. The group most neglected by current ITNs delivery strategies is children and adolescents aged between 519 years. This is a particularly important group for two reasons: a) they represent a large fraction of the population in most developing African communities (green bars shown in Figures 1a-1c); and b) while they may have developed a functional immune response against clinical disease before their fifth birthday $[29,30]$ they have not developed a parasitic immunity that regulates the risk of blood stage infection. To highlight this vulnerability, Figure 2 shows age-stratified estimates of ITNs use from the 2007 Kenya MIS for populations living at the coast and pre-intervention infection prevalence among populations living in the same area [31]. As with national estimates, ITNs coverage in Coastal Kenya [32] is lowest among those aged 5-19 years, a period when the prevalence of infection reaches a peak and represents the sustained highest levels of infection prevalence in the community. Notably, ITNs coverage increased in all segments of the population, but in the 5-19 year old age group, the increase in ITNs coverage was smallest of any age group. As expected this group represents the largest threat to the success of scaled, universal coverage of ITNs likely to impact upon reduced community-levels of transmission.

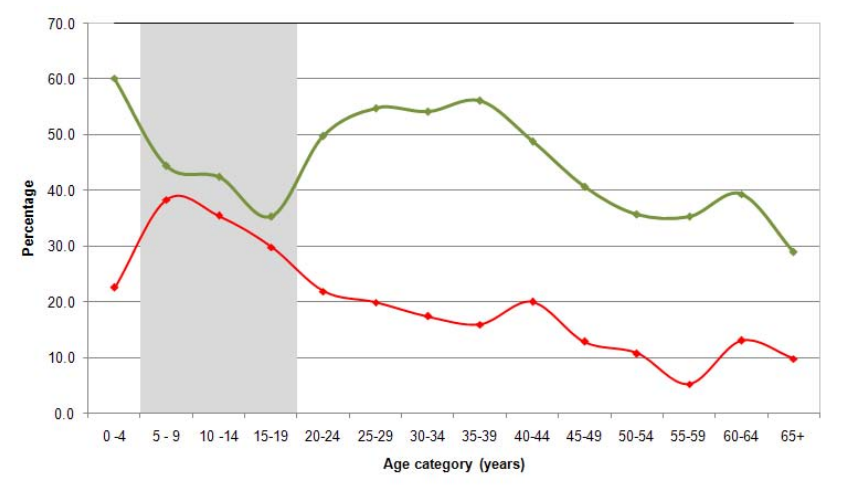

Figure 2

Graph showing the prevalence of infection (red line) among individuals of all ages in the Coast province of Kenya prior to scaled ITN delivery [ $3 \mathrm{I}]$ and the proportion of the population sleeping under an insecticide treated net (green line) in 2007 after the national free mass campaign of 2006 [32]. The graph illustrates that in Kenya the national ITNs scaling-up strategies have been sub-optimal in terms of targeting the populations aged 5-19 years (shaded grey), the age-group in which pre-intervention parasite prevalence was at its peak.
Operations research in Africa show that the pre-existing infrastructure of schools can cost-effectively deliver simple health interventions, including deworming and micronutrients, as well as feeding programmes [33]. In areas of high enrollment, where the majority of nonenrolled school age children have at least one sibling attending school and few differentials in enrollment by socio-economic and health status exists [34], school health programmes are likely to be extremely equitable. Even in areas of low enrollment, non-enrolled children can still benefit from school health programmes: experience in several African countries demonstrates that many out-of-school children will take advantage of services, such as deworming, provided through schools [33]. Such features of school-based programmes provide a potentially equitable and cost-effective framework for malaria control [34]. Already, drug-based approaches to the prevention of malaria infection and anaemia in this target population are being considered again [35-38] after popular chemoprophylaxis strategies for school children in Africa during the 1950s and 1960's [39-41]. Given the poor coverage of current ITN programmes as a means to prevent infection among school aged children, pragmatic trials or operational investigations of the impact of ITNs delivered to children attending school should be compared to the provision, separately or in combination, with drugs used for intermittent presumptive treatment. In addition there is need to increase effective communication to households to encourage optimum usage of ITNs to address the widespread problem of households often using only a proportion of the nets they own while some household members remain unprotected [42]. Effective use of these reserve nets will also reduce redundancy in ITNs distributions by national programmes.

\section{Conclusion}

In conclusion, the study shows that in malaria endemic African countries, school-age children are the least protected with ITNs. School-delivery of ITNs, therefore, should be considered as an approach to reach universal coverage and improve the likelihood of impacting upon malaria parasite transmission. As most sub-Saharan African countries move towards universal coverage of ITNs it becomes important that national survey data can be used to redefine optimal approaches to this new strategy. Therefore data on ITN use must be collected for all household members and not, as is the case with the MICs surveys and some DHS surveys, for those only under the age of five years and pregnant women.

\section{Abbreviations}

DHS: Demographic and Health Surveys; MIS: Malaria Indicator Surveys; MICS: Multiple Indicators Cluster Surveys; ITN: Insecticide Treated Nets; MDG: Millennium Development Goals. 


\section{Competing interests}

The authors declare that they have no competing interests.

\section{Authors' contributions}

AMN was responsible for data cleaning, analysis, interpretation and production of the final manuscript. VCK downloaded all the survey data, reconstructed the data and conducted preliminary analysis. SJB provided advice on analysis, interpretation of results and helped with the preparation of final manuscript. RWS was responsible for overall scientific management, analysis, interpretation and preparation of the final manuscript. All authors have read and approved the final version of the manuscript.

\section{Additional material}

\section{Additional file 1}

Use of insecticide treated nets by all ages. Plots of use of insecticide treated nets by age for each of the 18 countries presented in the manuscript Click here for file

[http://www.biomedcentral.com/content/supplementary/14712458-9-369-S1.DOC]

\section{Acknowledgements}

Victor Alegana is thanked for his help in data manipulation from the various websites. We thank Drs Dave Smith and Simon Hay for their comments on earlier versions of the manuscript. This paper is published with the permission of the director KEMRI.

\section{FUNDING SOURCE}

AMN is supported by the Wellcome Trust as a Research Training Fellow (\#081829). SB is supported by the Wellcome Trust as a Career Development Fellow (\#081673). RWS is supported by the Wellcome Trust as Principal Research Fellow (\#079080). This work forms part of the output of the Malaria Atlas Project (MAP, http://www.map.ox.ac.uk), principally funded by the Wellcome Trust, UK. We also acknowledge support from the Kenya Medical Research Institute. The funders had no role in study design, data collection and analysis, decision to publish, or preparation of the manuscript.

\section{References}

I. World Health Organization: World Malaria Report. Geneva: World Health Organization; 2005

2. Noor AM, Mutheu JJ, Tatem AJ, Hay SI, Snow RW: Insecticide treated net coverage in Africa: mapping progress in 20002007. Lancet 2009, 373:58-67.

3. Millennium Development Goals: Final report to United Nations Secretary General. London/Sterling VA: United Nations; 2005:356.

4. Binka FN, Indome F, Smith T: Impact of spatial distribution of permethrin-impregnated bed nets on child mortality in rural Northern Ghana. Am J Trop Med Hyg 1998, 59:80-85.

5. Howard SC, Omumbo J, Nevill CG, Some ES, Donnelly CA, Snow RW: Evidence for a mass community effect of insecticide treated bednets on the incidence of malaria on the Kenyan coast. T Roy Soc Trop Med H 2000, 94:357-360.

6. Maxwell CA, Msuya E, Sudi M, Njunwa KJ, Carneiro IA, Curtis CF: Effect of community-wide use of insecticide-treated nets for
3-4 years on malarial morbidity in Tanzania. Trop Med Int Health 2002, 7:1003-1008.

7. Gimnig JE, Kolczak MS, Hightower AW, Vulule JM, Schoute E, Kamau L, Phillips-Howard PA, ter Kuile FO, Nahlen BL, Hawley WA: Effect of permethrin-treated bed nets on the spatial distribution of malaria vectors in western Kenya. Am J Trop Med Hyg 2003, 68: $115-120$

8. Hawley WA, Phillips-Howard PA, ter Kuile FO, Terlouw DJ, Vulule JM, Ombok M, Nahlen BL, Gimnig JE, Kariuki SK, Kolczak MS, Hightower AW: Community-wide effects of permethrin-treated bednets on child mortality and malaria morbidity in western Kenya. Am / Trop Med Hyg 2003, 68: I2I-I27.

9. Killeen GF, Smith TA, Furguson HM, Mshinda H, Abdulla S, Lengeler $C$, Kachur SP: Preventing childhood malaria in Africa by protecting adults from mosquitoes with insecticide-treated nets. Plos Med 2007, 4:e229.

10. Smith DL, Noor AM, Hay SI, Snow RW: Predicting changing malaria risk after expanded insecticide treated net coverage in Africa. Trends Parasitol 2009. doi: I0.1016/j.pt.2009.08.002

II. Ross A, Killeen GF, Smith TA: Relationships of host infectivity to mosquitoes and asexual parasite density in Plasmodium falciparum. Am J Trop Med Hyg 2006, 75:32-37.

12. Miller JM, Korenromp EL, Nahlen BL, Steketee RW: Estimating the number of insecticide-treated nets required by African households to reach continent-wide malaria coverage targets. JAMA 2007, 297:224I-2250.

13. Roll Back Malaria, World Health Organization and United Nations Children Fund: World Malaria Report. Geneva, Switzerland 2008.

14. Eisele TP, Keating J, Littrell M, Larsen D, Macintyre K: Assessment of insecticide-treated bednet use among children and pregnant women across 15 countries using standardized national surveys. Am J Trop Med Hyg 2009, 80:209-2I4.

15. Korenromp EL, Miller J, Cibulskis RE, Kabir Cham M, Alnwick D, Dye $\mathrm{C}$ : Monitoring mosquito net coverage for malaria control in Africa: possession vs. use by children under $\mathbf{5}$ years. Trop Med Int Health 2003, 8:693-703.

16. Webster J, Lines J, Bruce J, Armstrong Schellenberg J, Hanson K: Which delivery systems reach the poor? A review of the equity of coverage of ever-treated nets, never-treated nets, and immunization to reduce child mortality in Africa. Lancet Infect Dis 2007, 5:709-7I7.

17. Roll Back Malaria: The global malaria action plan. In Roll Back Malaria partnership Geneva: World Health Organization; 2008.

18. Measure DHS [http://www.measuredhs.com]. Accessed June 2009

19. Roll Back Malaria-Monitoring and Evaluation Reference Group: Monitoring and Evaluation Resource Group. Core Household Questionnaire. [http://www.rollbackmalaria.org/partnership/wg/ wg monitoring/docs/mis2005/ccl.pdf]. Accessed I9 June 2009

20. UNICEF: Multiple Indicators Cluster Surveys. [http:// www.childinfo.org]. Accessed June 2009

21. UN: World Population Prospectus: 2008 edition. [http:// esa.un.org/unpp/index.asp?panel=2]. Accessed I4 June 2009

22. Killeen GF, Tami A, Kihonda J, Okumu FO, Kotas ME, Grundmann H, Kasigudi N, Ngonyani H, Mayagaya V, Nathan R, Abdulla S, Charlwood JD, Smith TA, Lengeler C: Cost-sharing strategies combining targeted public subsidies with private-sector delivery achieve high bednet coverage and reduced malaria transmission in Kilombero Valley, southern Tanzania. BMC Infect Dis 2007, 7:12.

23. Bernard J, Mtove G, Mandike R, Mtei F, Maxwell C, Reyburn H: Equity and coverage of insecticide-treated bed nets in an area of intense transmission of Plasmodium falciparum in Tanzania. Malaria J 2009, 8:65.

24. Matovu F, Goodman C, Wiseman V, Mwengee W: How equitable is bed net ownership and utilisation in Tanzania? A practical application of the principles of horizontal and vertical equity. Malaria I 2009, 8:109.

25. Noor AM, Moloney G, Borle M, Fegan GW, Shewshuk T, Snow RW: The use of mosquito nets and the prevalence of Plasmodium falciparum infection in rural South Central Somalia. PLoS One 2008, 3:e208I.

26. Shargie EB, Gebre T, Ngondi J, Graves PM, Mosher AW, Emerson PM, Ejigsemahu Y, Endeshaw T, Olana D, WeldeMeskel A, Teferra A, Tadesse Z, Tilahun A, Yohannes G, Richards FO: Malaria prevalence and mosquito net coverage in Oromia and SNNPR regions of Ethiopia. BMC Public Health 2008, 8:32I. 
27. Afolabi BM, Sofola OT, Fatunmbi BS, Komakech W, Okoh F, Saliu O, Otsemobor P, Oresanya OB, Amajoh CN, Fasiku D, Jalingo I: Household possession, use and non-use of treated or untreated mosquito nets in two ecologically diverse regions of NigeriaNiger Delta and Sahel Savannah. Malaria J 2009, 8:30.

28. Webster J, Hill J, Lines J, Hanson K: Delivery systems for insecticide treated and untreated mosquito nets in Africa: categorization and outcomes achieved. Health Policy Plann 2005, 22:1-17.

29. Snow RW, Omumbo JA, Lowe B, Molyneux SM, Obiero JO, Palmer A, Weber MW, Pinder M, Nahlen B, Obonyo C, Newbold C, Gupta $S$, Marsh K: Relation between severe malaria morbidity in children and level of Plasmodium falciparum transmission in Africa. Lancet 1997, 349:1650-1654.

30. Snow RW, Marsh K: The consequences of reducing Plasmodium falciparum transmission in Africa. Adv Parasitol 2002, 52:235-264.

31. Mwangi TW, Ross A, Snow RW, Marsh K: Case definitions of clinical malaria under different transmission conditions in Kilifi District, Kenya. J Infect Dis 2005, 191:1932-1939.

32. Ministry of Health Kenya: Kenya national malaria indicator survey 2007. Nairobi, Kenya: Ministry of Health; 2009.

33. Bundy DAP, S Shaeffer, MCH Jukes, et al.: School-based health and nutrition programs. In Disease control priorities for developing countries 2nd edition. Edited by: Jamison DT, Breman JG, Measham AR, et al. Oxford University Press: Oxford; 2006:1091-1108.

34. Filmer $D$, Pritchett $L$ : The effect of household wealth on educational attainment: evidence from $\mathbf{3 5}$ countries. Pop Dev Rev 1999, 25:85-120.

35. Brooker S, Clarke S, Snow RW, Bundy DA: Malaria in African schoolchildren - options for control. T Roy Soc Trop Med H 2008, 102:304-305.

36. Pasha O, Del Rosso J, Mukaka M, Marsh D: The effect of providing fansidar (sulfadoxine-pyrimethamine) in schools on mortality in school-age children in Malawi. Lancet 2003, 361:577-578.

37. Clarke SE, Jukes MCH, Njagi K, Khasakhala L, Cundill B, Otido J, Crudder C, Estambale B, Brooker S: Effect of intermittent preventive treatment on health and education in schoolchildren: a cluster-randomised, double-blind, placebocontrolled trial. Lancet 2008, 372:127-138.

38. Barger B, Maiga H, Traore OB, Tekete M, Tembine I, Dara A, Traore Zl, Gantt S, Doumbo K, Djimde AA: Intermittent preventive treatment using artemisinin-based combination therapy reduces malaria morbidity among school-aged children in Mali. Trop Med Int Health 2009, 14:1-8.

39. Colbourne $M$ : The effect of malaria supression in a group of Accra school children. T Roy Soc Trop Med H 1 955, 49(4):356-369.

40. Clyde DF, Shute GT: Comparative trials of tasteless chloroquine methylene-hydroxynaphthoate and diphosphate salts of choloroquine among Tanganyika school children. Anna Trop Med Hyg 1958, 52:5I-54.

41. Clyde DF: Drug prophylaxis of malaria amongst premunized school children. East African Medical Journal 1959, 36:12-25.

42. World Health Organization: World Malaria Report 2008. Prepared by Roll Back Malaria, World Health Organization and United Nations Children Fund. Geneva, Switzerland; 2008. WHO/HTM/ GMP/2008.I

\section{Pre-publication history}

The pre-publication history for this paper can be accessed here:

http://www.biomedcentral.com/1471-2458/9/369/pre pub
Publish with Bio Med Central and every scientist can read your work free of charge

"BioMed Central will be the most significant development for disseminating the results of biomedical research in our lifetime. "

Sir Paul Nurse, Cancer Research UK

Your research papers will be:

- available free of charge to the entire biomedical community

- peer reviewed and published immediately upon acceptance

- cited in PubMed and archived on PubMed Central

- yours - you keep the copyright
BioMedcentral 